Cite this: RSC Advances, 2013, 3, 10427

Received 13th February 2013,

Accepted 1st May 2013

DOI: $10.1039 / c 3 r a 40774 h$

www.rsc.org/advances

\title{
Beyond gold: rediscovering tetrakis-(hydroxymethyl)- phosphonium chloride (THPC) as an effective agent for the synthesis of ultra-small noble metal nanoparticles and Pt-containing nanoalloys ${ }^{\dagger}$
}

\author{
José L. Hueso, *ab Víctor Sebastián, a Álvaro Mayoral, ac Laura Usón, a Manuel Arrueboab \\ and Jesús Santamaría*ab
}

The use of tetrakis-(hydroxymethyl)-phosphonium chloride (THPC) as simultaneous reducing agent and stabilizing ligand has been extended to the single-step synthesis at room temperature of a wide variety of monometallic nanoparticles and bi-/tri- metallic nanoalloys containing noble metals with potential application in catalysis. The colloidal suspensions exhibit mean diameters below $4 \mathrm{~nm}$ with narrow size distributions and high stability in aqueous solution for long periods of time.

\section{Introduction}

Noble metal nanoparticles continue to attract strong interest on account of their fascinating properties and potential applications in sensing, electronic devices, biomedicine, imaging and catalysis. ${ }^{1,2}$ Because of this, numerous bottomup synthetic approaches have been explored with the aim of generating colloidal suspensions of metal nanoparticles with controlled size and shape. However, general synthesis methods of single-metal nanoparticles are scarce and remain as an even more formidable challenge for bi- or trimetallic systems. ${ }^{3-10}$ Thermal decomposition of organometallic compounds and metal-surfactant complexes in the presence of surfactants and stabilizing polymers yields narrowly distributed and well-crystallized nanoparticles but purification requires multiple and tedious steps..$^{6,11,12}$ On the other hand, the chemical reduction of metal salt precursors, either in aqueous or organic phase, is a widely extended strategy to obtain metallic nanostructures. ${ }^{4,6-8,11-13}$ In this approach a reducing agent is mixed with the metal precursor salt in the presence of stabilizing agents (ligands, polymers or surfactants) that prevent agglomeration by electrostatic stabilization

\footnotetext{
${ }^{a}$ Institute of Nanoscience of Aragon (INA) and Department of Chemical Engineering and Environmental Technology, University of Zaragoza, C/Mariano Esquillor, s/n, I+D+i Building, 50018, Zaragoza, Spain. E-mail: jlhueso@unizar.es;

jesus.santamaria@unizar.es; Fax: +34 976 761879; Tel: +34 876555442

${ }^{b}$ CIBER de Bioingeniería, Biomateriales y Nanomedicina (CIBER-BBN), Campus Río Ebro-Edificio I+D, 50018-Zaragoza, Spain

${ }^{c}$ Advanced Microscopy Laboratory, University of Zaragoza, 50018, Zaragoza, Spain † Electronic supplementary information (ESI) available: Additional TEM/STEM images, EDX analysis, particle size distribution of fresh monometallic, bimetallic and trimetallic nanoparticles and some selected aged colloidal samples are included. See DOI: 10.1039/c3ra40774h
}

(coulombic repulsion) or by the coupling of large molecules (steric hindrance).

The formation of stable metal organosols can be attained by refluxing with $\alpha$-alcohols which act as solvent and reducing agents simultaneously (i.e. diols or ethyleneglycol (EG)). This polyol-reduction method developed by Hirai and Toshima ${ }^{8,14,15}$ yields a wide variety of small and monodisperse metal nanoparticles. Nevertheless, heating at high temperatures and the presence of other stabilizing and polymers such as poly(vinylpyrrolidone) (PVP) or poly(vinyl alcohol) (PVA) is generally required. ${ }^{6-8,16}$ Other stabilizing agents have been reported in the literature including PEG, hexadecyltrimethylammonium bromide (CTABr), sodium dodecyl sulphate (SDS) or amines (chitosan, polyethylenimine (PEI)). An interesting development is the use of molecules that can act simultaneously as reducing and stabilizing agents thereby limiting the number of required reactants. This is the case of the so-called Turkevich method ${ }^{21,22}$ where sodium citrate is employed simultaneously as ionic stabilizer and reductant through the in situ generation of acetone dicarboxylate (an oxidation product of citrate) that is actually the chemical intermediate required to further reduce the metal salt precursors. ${ }^{21-25}$ PEI and octadecylamine (ODA) are other interesting examples of polymer and alkyl-based amines ${ }^{13,26,27}$ with dual role as steric/ chelating stabilizer and reducing capabilities.

Almost two decades ago, Duff et al. proposed a new method for the synthesis of gold nanoparticles at room temperature, ${ }^{20}$ that involved the use of a low-chain compound with a reducing and ionic stabilizing dual role in aqueous phase. The compound is the organophosphorus salt tetrakis-(hydroxymethyl)-phosphonium chloride, $\mathrm{P}\left(\mathrm{CH}_{2} \mathrm{OH}\right)_{4} \mathrm{Cl}$ (hereafter termed THPC) which corresponds to Structure I in Scheme 1. 


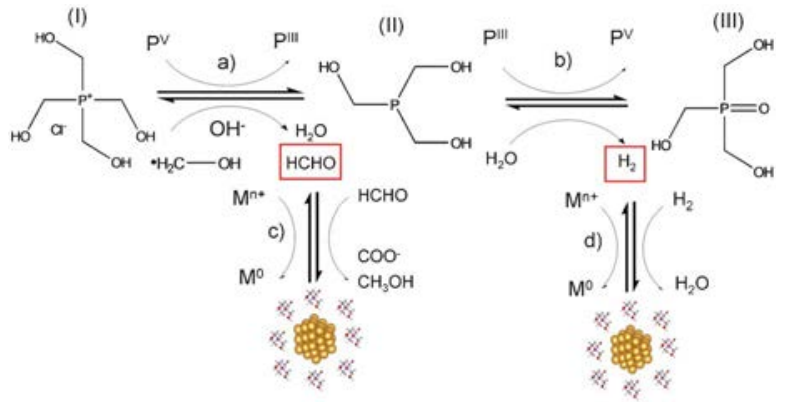

Scheme 1 Proposed reaction pathways for the generation of metal nanoparticles, involving the conversion of THPC (Structure I) into THPO (Structure III), and the in situ generation of formaldehyde and hydrogen as active reducing agents. Partly based on ref. 17-20.

However, according to Duff et al., ${ }^{20}$ this intermediate has enough reducing power to produce hydrogen from water, as depicted in Scheme 1 (step b) while evolving to THPO (Structure III) . In our case the formation of hydrogen was corroborated by the continuous bubbling flow detected at the beginning of the reaction. The in situ generated formaldehyde and hydrogen facilitate the formation of metallic nanoparticles. Formaldehyde evolves to methanol or formiate via a methylene glycolate anion intermediate that acts as the effective reducing species ${ }^{28,29}$ (step $\mathrm{c}$ in Scheme 1) and $\mathrm{H}_{2}$ undergoes oxidation to $\mathrm{H}_{2} \mathrm{O}$ (step d in Scheme 1) as reported for stabilized $\mathrm{Pd}, \mathrm{Pt}, \mathrm{Rh}$ or $\mathrm{Ir}$ sols in the presence of hydrogen. ${ }^{25}$ In this work we have revisited the synthesis proposed by Duff et $a .^{20}$ and extended it beyond gold, enabling the production of a variety of ultra-small monometallic, bimetallic and trimetallic noble-metal nanoparticles with $80-85 \%$ yields. We achieved this while employing essentially the same protocol as Duff et $a l^{20,30,31}$ with only small differences regarding the THPC/Metal molar ratios and reaction times used. The results shed light on the role played by THPC and formaldehyde in the overall reaction scheme.

\section{Experimental section}

\section{Chemicals}

Tetrakis(hydroxymethyl) phosphonium chloride solution (THPC, $80 \mathrm{wt} \%$ Aldrich), poly(vinyl pyrrolidone) (PVP, MW $\approx$ $10000 \mathrm{Da}$, Aldrich), chloroplatinic acid $8 \mathrm{wt} \%$ solution ( $\mathrm{HPtClO}_{4}, \quad$ Aldrich), potassium tetrachloropalladate(II) $\left(\mathrm{K}_{2} \mathrm{PdClO}_{4}\right.$, Aldrich), tetrachloroauric acid, trihydrate $\left(\mathrm{HAuCl}_{4} \cdot 3 \mathrm{H}_{2} \mathrm{O}\right.$, Aldrich), ruthenium(III) chloride $\left(\mathrm{RuCl}_{3}\right.$, Aldrich), rhodium(III) chloride hydrate $\left(\mathrm{RhCl}_{3}\right.$, Aldrich), and sodium hydroxide ( $\mathrm{NaOH}$, Aldrich) were all used as received.

\section{Synthesis of gold nanoparticles}

For the synthesis of $\mathrm{Au}$ nanoparticles, $3.0 \mathrm{mg}$ of $\mathrm{HAuCl}_{4}$ was added to $15 \mathrm{~mL}$ of distilled water in a glass vial under magnetic stirring. Afterwards, $333 \mu \mathrm{L}$ of a $65 \mathrm{mM}$ THPC solution was added. After several minutes, $165 \mu \mathrm{L}$ of a $1 \mathrm{M}$ $\mathrm{NaOH}$ solution was added to the glass vial. The reaction mixture was kept at room temperature for 4 days, wrapping an aluminium foil to preserve the reaction mixture from photothermal decomposition. The product was kept in a refrigerator until further characterization.

\section{Synthesis of platinum nanoparticles}

In a typical synthesis of Pt nanoparticles, $100 \mu \mathrm{L}$ of $\mathrm{HPtClO}_{4}$ $8 \mathrm{wt} \%$ solution was added to $15 \mathrm{~mL}$ of distilled water in a glass vial under magnetic stirring. Meanwhile, $333 \mu \mathrm{L}$ of a $65 \mathrm{mM}$ THPC solution was added. After several minutes, $165 \mu \mathrm{L}$ of a 1 $\mathrm{M} \mathrm{NaOH}$ solution was added to the glass vial. The reaction mixture was kept at room temperature for 4 days, wrapping an aluminium foil to preserve the reaction mixture from photothermal decomposition. The product was kept in a refrigerator until further characterization.

\section{Synthesis of palladium nanoparticles}

For the synthesis of Pd nanoparticles, $6.7 \mathrm{mg}$ of $\mathrm{K}_{2} \mathrm{PdClO}_{4}$ was added to $15 \mathrm{~mL}$ of distilled water in a glass vial under magnetic stirring. Meanwhile, $75 \mathrm{mg}$ of PVP and $333 \mu \mathrm{L}$ of a 65 mM THPC solution were added. After several minutes, $165 \mu \mathrm{L}$ of a $1 \mathrm{M} \mathrm{NaOH}$ solution was added to the glass vial. The reaction mixture was kept at room temperature for 4 days, wrapping an aluminium foil to preserve the reaction mixture from photothermal decomposition. The product was kept in a refrigerator until further characterization.

\section{Synthesis of ruthenium nanoparticles}

For the synthesis of $\mathrm{Ru}$ nanoparticles, $4.3 \mathrm{mg}$ of $\mathrm{RuCl}_{3}$ was added to $15 \mathrm{~mL}$ of distilled water in a glass vial under magnetic stirring. Afterwards, $333 \mu \mathrm{L}$ of a $65 \mathrm{mM}$ THPC solution was added. After several minutes, $165 \mu \mathrm{L}$ of a $1 \mathrm{M}$ $\mathrm{NaOH}$ solution was added to the glass vial. The reaction mixture was kept at room temperature for 4 days, wrapping an aluminium foil to preserve the reaction mixture from photothermal decomposition. The product was kept in a refrigerator until further characterization.

\section{Synthesis of platinum-gold bimetallic nanoparticles}

In a typical synthesis of Pt-Au nanoparticles, $100 \mu \mathrm{L}$ of $\mathrm{HPtClO}_{4} 8 \%$ solution and $300 \mu \mathrm{L}$ of $\mathrm{HAuCl}_{4} 30 \mathrm{mM}$ solution and were added to $15 \mathrm{~mL}$ of distilled water in a glass vial under magnetic stirring. Meanwhile, $333 \mu \mathrm{L}$ of a $65 \mathrm{mM}$ THPC solution was added. After several minutes, $165 \mu \mathrm{L}$ of a $1 \mathrm{M}$ $\mathrm{NaOH}$ solution was added to the glass vial. The reaction mixture was kept at room temperature for 4 days, wrapping an aluminium foil to preserve the reaction mixture from photothermal decomposition. The product was kept in a refrigerator until further characterization.

\section{Synthesis of platinum-palladium bimetallic nanoparticles}

For the synthesis of Pt-Pd nanoparticles, $50 \mu \mathrm{L}$ of $\mathrm{HPtClO}_{4} 8 \%$ solution and $3.1 \mathrm{mg}$ of $\mathrm{K}_{2} \mathrm{PdClO}_{4}$ were added to $15 \mathrm{~mL}$ of distilled water in a glass vial under magnetic stirring. Afterwards, $333 \mu \mathrm{L}$ of a $65 \mathrm{mM}$ THPC solution was added to the glass vial and several minutes later, $165 \mu \mathrm{L}$ of a $1 \mathrm{M} \mathrm{NaOH}$ solution was dropped. The reaction mixture was kept at room temperature for 4 days, wrapping an aluminium foil to preserve the reaction mixture from photothermal decomposi- 
tion. The product was kept in a refrigerator until further characterization.

\section{Synthesis of platinum-ruthenium bimetallic nanoparticles}

$\mathrm{Pt}-\mathrm{Ru}$ nanoparticles were synthesised as follows: $50 \mu \mathrm{L}$ of $\mathrm{HPtClO}_{4} 8 \mathrm{wt} \%$ solution and $2.1 \mathrm{mg}$ of $\mathrm{RuCl}_{3}$ were added to 15 $\mathrm{mL}$ of distilled water in a glass vial under magnetic stirring. Then, $333 \mu \mathrm{L}$ of a $65 \mathrm{mM}$ THPC solution was added to the glass vial and afterwards, $165 \mu \mathrm{L}$ of a $1 \mathrm{M} \mathrm{NaOH}$ solution was added dropwise. The reaction mixture was kept at room temperature for 4 days, wrapping an aluminium foil to preserve the reaction mixture from photothermal decomposition. The product was kept in a refrigerator until further characterization.

\section{Synthesis of platinum-rhodium bimetallic nanoparticles}

Pt-Rh nanoparticles were synthesised as follows: $50 \mu \mathrm{L}$ of $\mathrm{HPtClO}_{4} 8 \mathrm{wt} \%$ solution and $2.1 \mathrm{mg}$ of $\mathrm{RhCl}_{3}$ were added to 15 $\mathrm{mL}$ of distilled water in a glass vial under magnetic stirring. Then, $333 \mu \mathrm{L}$ of a $65 \mathrm{mM}$ THPC solution was added to the glass vial and afterwards, $165 \mu \mathrm{L}$ of a $1 \mathrm{M} \mathrm{NaOH}$ solution was added dropwise. The reaction mixture was kept at room temperature for 4 days, wrapping an aluminium foil to preserve the reaction mixture from photothermal decomposition. The product was kept in a refrigerator until further characterization.

\section{Synthesis of platinum-palladium-rhodium trimetallic nanoparticles}

For the synthesis of Pt-Pd-Rh nanoparticles, $33 \mu \mathrm{L}$ of $\mathrm{HPtClO}_{4}$ $8 \mathrm{wt} \%$ solution, $1.4 \mathrm{mg}$ of $\mathrm{RhCl} 3$ and $2.2 \mathrm{mg}$ of $\mathrm{K}_{2} \mathrm{PdClO}_{4}$ were added to $15 \mathrm{~mL}$ of distilled water in a glass vial under magnetic stirring. After mixing, $333 \mu \mathrm{L}$ of a $65 \mathrm{mM}$ THPC solution was added to the glass vial and several minutes later, $165 \mu \mathrm{L}$ of a $1 \mathrm{M} \mathrm{NaOH}$ solution was added dropwise. The reaction mixture was kept at room temperature for 4 days, wrapping an aluminium foil to preserve the reaction mixture from photothermal decomposition. The product was kept in a refrigerator until further characterization.

\section{Characterization methods}

Preliminary electron microscopy observations were carried out using a T20-FEI microscope with a LaB6 electron source fitted with a "SuperTwin $(\mathbb{R}$ " objective lens allowing a point to point resolution of $2.4 \AA$ A. Aberration corrected scanning transmission electron microscopy images were acquired using a high angle annular dark field detector in a FEI XFEG TITAN electron microscope operated at $300 \mathrm{kV}$ equipped with a CETCOR Csprobe corrector from CEOS Company allowing forming an electron probe of $0.08 \mathrm{~nm}$. The geometric aberrations of the probe-forming system were controlled to allow a beam convergence of 24.7 mrad half-angle to be selected. Elemental analysis was carried out with EDS (EDAX) detector which allows performing EDX experiments in scanning mode.

\section{Results and discussion}

\section{Monometallic nanoparticles}

Fig. 1 shows a representative selection of aberration corrected (Cs) STEM-HAADF images of monometallic Au, Pt, Pd and Ru nanoparticles synthesized following the specific conditions described in the experimental section (see also further experimental details in Fig. S1-S4 enclosed in the ESI. $†$ For gold, in addition to the cubic nanoparticles (fcc symmetry) decahedral and icosahedral structures are also present, with a relatively wide size distribution of 2-4 nm. A certain tendency to coalescence and coarsening is observed, as previously reported by Duff et $a l^{32,33}$ that can be minimized if the samples are stored at $4{ }^{\circ} \mathrm{C}^{33}$ In the case of the $\mathrm{Pt}$ nanoparticles, well-crystallized structures of $1.5 \mathrm{~nm}$ were observed (Fig. 1b and S2 in ESI $\dagger$ ) which could be indexed according to the Fm-3m space group (Fig. 1b recorded along the [110] orientation). In addition to minimal interparticle coalescence which was mainly induced by the electron beam irradiation, ${ }^{34}$ it is also worth mentioning the presence of clusters of less than $1 \mathrm{~nm}$ with no clear lattice order (see Fig. S2, ESI $\dagger$ ). Similar to the Pt synthesis Pd nanoparticles exhibit clear lattice fringes corresponding to fcc symmetry. Finally, the $\mathrm{Ru}$ hydrosols obtained by this method show mean size diameters of barely $2.2 \mathrm{~nm}$ (see Fig. S4, ESI $\dagger$ ), lower crystallinity degree and a higher tendency to coalescence than the other monometallic nanoparticles.

These differences in crystalline order and size distribution from gold to ruthenium follow the expected trend, taking into account the reduction potential values for each of the metal ionic precursors: ${ }^{35} E^{0}\left(\mathrm{Au}^{3+} / \mathrm{Au}\right)=1.498 \mathrm{~V}>E^{0}\left(\mathrm{Pt}^{2+} / \mathrm{Pt}\right)=1.18 \mathrm{~V}$ $>E^{0}\left(\mathrm{Pd}^{2+} / \mathrm{Pd}\right)=0.951 \mathrm{~V}>E^{0}\left(\mathrm{Ru}^{3+} / \mathrm{Ru}\right)=0.386 \mathrm{~V}$. Given the higher reduction potential values for gold and platinum, the formation of nascent metallic nuclei and subsequent growth

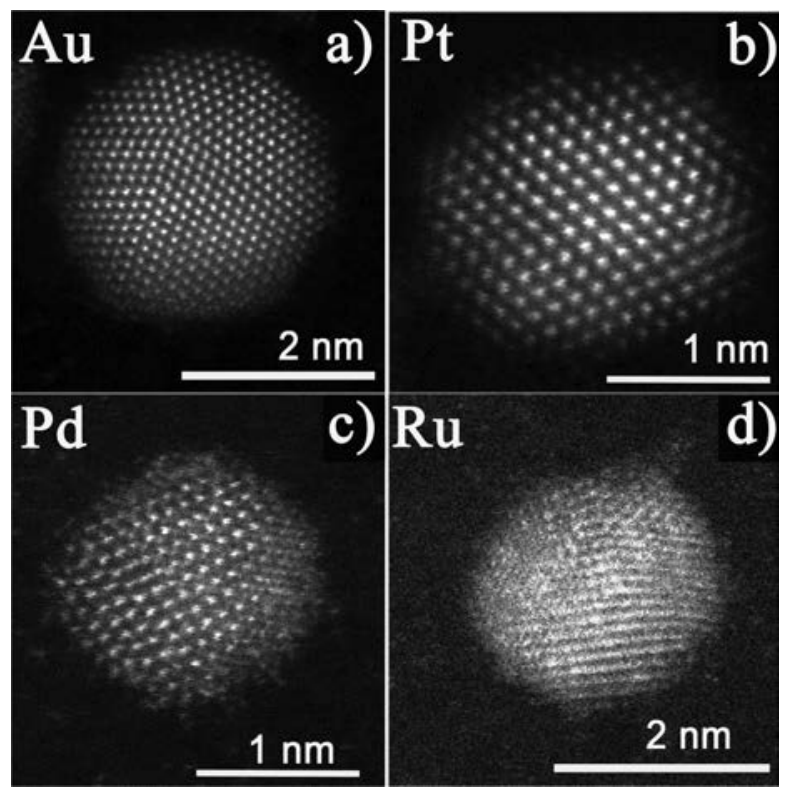

Fig. 1 STEM images of different monometallic nanoparticles synthesized by the THPC method: (a) Au; (b) Pt; (c) Pd; (d) Ru. 
are kinetically more favoured. An earlier formation of $\mathrm{Au}$ and $\mathrm{Pt}$ nuclei means that, for a given total reaction time, $\mathrm{Au}$ and $\mathrm{Pt}$ nanoparticles have more time to grow, producing bigger crystals or a better crystalline ordering. The opposite can be expected for $\mathrm{Pd}$ and $\mathrm{Ru}$ that give rise to smaller and less mature crystalline structures that give rise to less ordered structures. For all the single metal nanoparticles investigated the hydrosols presented excellent colloidal stability, without precipitation or agglomeration over a period of several months. Moreover, we have carried out an additional analysis of Pt nanoparticles after an aging period of 4 months (stored at $4{ }^{\circ} \mathrm{C}$ ) (see Fig. S8, ESI $\dagger$ ). STEM observations indicated minimal differences in morphology and interparticle coalescence and only a slightly wider size distribution.

Control experiments to determine the dual role of THPC as ligand and stabilizer. Additional experiments were carried out to elucidate the role of different species in the proposed reaction scheme: (i) the stabilizing role of THPC; (ii) the influence of the alkaline media to activate the reducing power of THPC (Step a in Scheme 1) and (iii) the influence of formaldehyde in the generation of the hydrosols (see Fig. S12 and S13 in the ESI $\dagger$ for further experimental details). In a first experiment, the platinum salt precursor was mixed with THPC in the absence of $\mathrm{NaOH}$. After 4 days of stirring no evidence of nanoparticle formation and darkening of the solution could be observed (Fig. S12a, ESI $\dagger$ ). In a second test, the same sequence of reagents was added but after several minutes, a $12 \mathrm{~mL}$ formaldehyde solution (amount calculated according to the stoichiometric formation of formaldehyde in the decomposition of THPC, assuming a single mol of formaldehyde formed) was injected in a continuous mode at a flow rate of $3 \mu \mathrm{L}$ $\min ^{-1}$. The reaction vial was sealed with a septum to prevent formaldehyde evaporation and kept at room temperature for 4 days, wrapped in aluminium foil to preserve the reaction mixture from photothermal decomposition. The formation of Pt nanoparticles was detected by visual inspection of the vial (see Fig. S12b, ESI $\dagger$ ) and the Cs corrected STEM analysis of the colloidal dispersion (Fig. S13, ESI†). Finally, the stabilizing role of THPC could be corroborated with a third experiment where the conditions were identical to the experiment-2 except for the absence of THPC. In this case, the Pt nanoparticles were formed due to the reducing power of formaldehyde, but without the presence of THPC, interparticle growth and aggregation could not be prevented and large agglomerates were formed after 1-2 days of reaction (Fig. S12c, ESI $\dagger$ ), giving rise to a black precipitate. Therefore, we can conclude that THPC behaves as an electrostatic stabilizer probably due to the presence of remaining chloro-ligands and positively charged phosphonium centres. ${ }^{31,36}$ We can also confirm that formaldehyde is an efficient reducing agent for the generation of metallic hydrosols in the presence of THPC (see TEM images in Fig. S13, ESI $\dagger$ ).

\section{Bimetallic nanoparticles}

The capacity of THPC to form bimetallic and tri-metallic alloys was also tested. Previous works by Rao and co-workers proved the reducing capacity of THPC to form nanocrystalline alloy films but using additional stabilizing organic ligands. ${ }^{37,38}$ In our case, Pt-containing structures were selected, given their widespread use in homogeneous and heterogeneous cataly$\operatorname{sis}^{39-51}$ and no additional ligands or stabilizers were added. Attaining homogeneity in the atomic distribution of bimetallic NPs is challenging because of the complex nucleation and growth kinetics of bimetallic systems. Nevertheless, it has been also reported that the spontaneous formation of alloys is favoured in the nanometer size range due to the lowering of the immiscibility gap that takes place as the size is reduced to nanometric dimensions and occurs via solid-state processes. $^{52-56}$ For instance, a remarkably high gap exists for bulk gold and platinum at temperatures below $500{ }^{\circ} \mathrm{C}^{57}$ but recent studies have shown that homogeneous $\mathrm{Pt}-\mathrm{Au}$ alloys can be formed at moderate temperatures. ${ }^{55,56}$ In our case, the use of THPC and the equimolar addition of different metal salt precursors yielded bimetallic nanoalloys at room temperature as shown in Fig. 2a and S5, ESI.† The Pt-Au NPs show clear lattice fringes for fcc symmetry and a homogeneous size distribution with a mean size close to $2 \mathrm{~nm}$ (Fig. S5, ESI $\dagger$ ). Likewise, Pt-Ru, Pt-Rh and Pt-Pd bimetallic nanoparticles of a similar size were also successfully prepared as shown in Fig. 2 and S6-S8, ESI. $†$

Cs corrected STEM-EDX analysis over multiple individual particles was carried out in order to determine the composition of those binary alloys. In spite of the inherently low EDS signal collected and the progressive degradation of the individual nanoparticles under the electron beam, overall mean compositions of $\mathrm{Pt}_{45} \mathrm{Au}_{55}, \mathrm{Pt}_{40} \mathrm{Ru}_{60}, \mathrm{Pt}_{40} \mathrm{Rh}_{60}$ and $\mathrm{Pt}_{60} \mathrm{Pd}_{40}$ could be obtained after the examination of multiple individual nanoparticles that exhibited mean diameters of 1.8$2.6 \mathrm{~nm}$ (see Fig. S5-S8, ESI $\dagger$ for size distributions). The exact distribution of the different atoms within the lattice structure

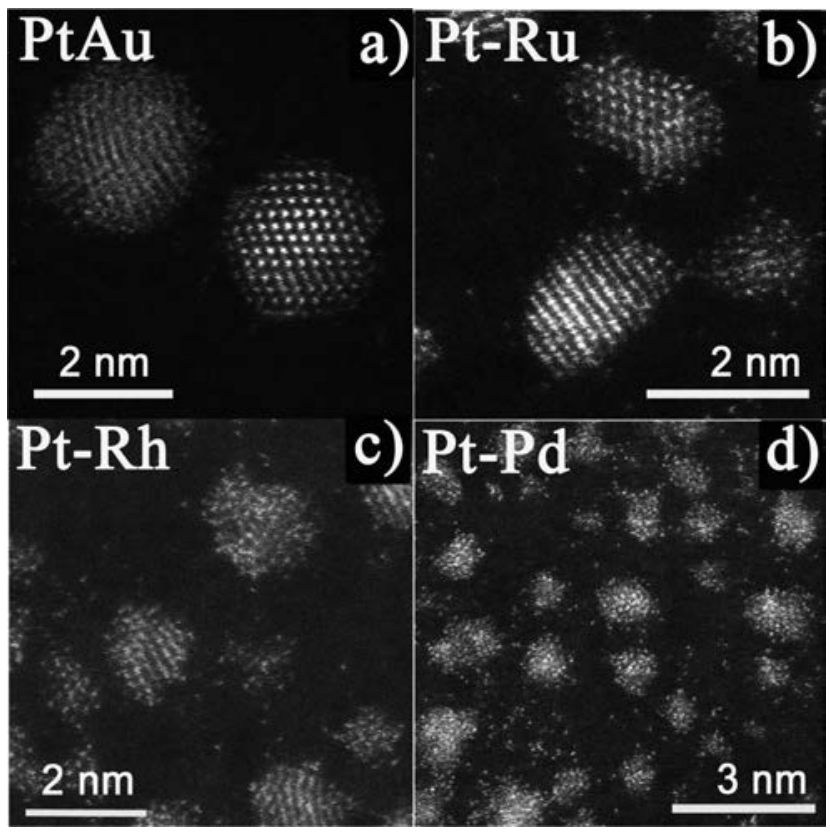

Fig. 2 STEM-HAADF images corresponding to different bimetallic nanoparticles synthesized using THPC as reducing and stabilizer agent: (a) $\mathrm{Pt}_{45} \mathrm{Au}_{55}$; (b) $\mathrm{Pt}_{40} \mathrm{Ru}_{60}$; (c) $\mathrm{Pt}_{40} \mathrm{Rh}_{60}$; (d) $\mathrm{Pt}_{60} \mathrm{Pd}_{40}$. Average compositions determined by EDS analysis from multiple nanoparticles (see also ESIt) 
could not be determined due to the extremely small size of the particles and the difficulty in obtaining spatially resolved EDS data from such small particles at atomic resolution. ${ }^{43}$ Nevertheless, the analysis is precise enough to rule out the existence of core-shell structures, or of large phase segregations, clearly suggesting the formation of alloys. The $\mathrm{Pt} / \mathrm{M}$ measured atomic ratios are between 0.67 and 1.5, with three Pt-deficient structures (with $\mathrm{Au}, \mathrm{Ru}$ and $\mathrm{Rh}$ ) and one with Pt in excess (with Pd). Interestingly, small Pt clusters with no ordering could be detected by STEM-EDS in the case of Ru and $\mathrm{Rh}$, but not for $\mathrm{Au}$ or Pd.

The composition of the bimetallic structures and the presence of isolated Pt clusters in the case of Pt-Ru and Pt$\mathrm{Rh}$ can also be explained as a consequence of the kinetics of particle nucleation and growth, driven by the reduction potentials of each metal. Au has a larger value of $E^{0}$ and is expected to give rise to Au-rich (i.e. Pt-deficient) structures. ${ }^{4}$ The reverse situation is observed for the Pt-Pd pair, where the $E^{0}$ for $\mathrm{Pt}$ reduction is larger and consequently $\mathrm{Pt}$ rich bimetallic structures are obtained. It should be noticed that the difference in $E^{0}$ values between $\mathrm{Au}$ and $\mathrm{Pt}$, and between $\mathrm{Pt}$ and Pd is moderate ( 0.32 and $0.23 \mathrm{~V}$, respectively). The larger differences are obtained between Pt and $\mathrm{Rh}$ or $\mathrm{Ru}(0.422$ and $0.794 \mathrm{~V}$ respectively). In this case the difference in favour of $\mathrm{Pt}$ is large enough to allow the nucleation of small Pt clusters before the reduction of $\mathrm{Ru}$ or $\mathrm{Rh}$ takes place, as observed experimentally. A high colloidal stability was also observed for the dispersions of bimetallic nanoparticles which remained stable after several months stored at $4{ }^{\circ} \mathrm{C}$. Pt-Ru NPs were selected for a detailed re-evaluation after 4 months and while the mean diameter size remained at $1.8 \mathrm{~nm}$, only a slight increase in the degree of polydispersity was observed (see Fig. S10, ESI $t$ ). However, the average composition had changed to $\mathrm{Pt}_{55} \mathrm{Ru}_{45}$ in comparison with the as-prepared initial Ptdeficient nanoparticles. Likewise, a less extended number of isolated Pt nanoclusters were detected by TEM. This indicates that the incorporation of Pt to the Pt-Ru nanoparticles has been taking place via dissolution-diffusion of the smaller Pt clusters along the aging process. ${ }^{4}$

\section{Trimetallic nanoparticles}

Finally, a ternary Pt-Rh-Pd alloy has been also prepared in order to assess the ability of the THPC-assisted synthesis method to deliver trimetallic NPs. Previous efforts to obtain trimetallic nanoparticles have been mainly focused on Ptbased alloys with application in electrocatalysis and fuel cells. ${ }^{5,58-62}$ These ternary alloys mainly contained $\mathrm{Pt}$, Ru and a third transition metal that in most cases was rapidly segregated as an oxide/hydroxide unless a subsequent reduction process at high temperature was carried out. ${ }^{58}$ Fig. 3 shows a Cs corrected STEM image of the Pt-Rh-Pd trimetallic nanoparticles prepared in this work. The nanoparticles present mean diameters of $2 \mathrm{~nm}$ and a narrow size distribution. A detailed image of a representative individual nanoparticle shows good crystallinity which could correspond to fcc symmetry. The EDX spectrum analysis reveals that these ternary alloys exhibit a Pt-enriched phase with an overall $\mathrm{Pt}_{45} \mathrm{Rh}_{27} \mathrm{Pd}_{28}$ composition (Fig. 3).

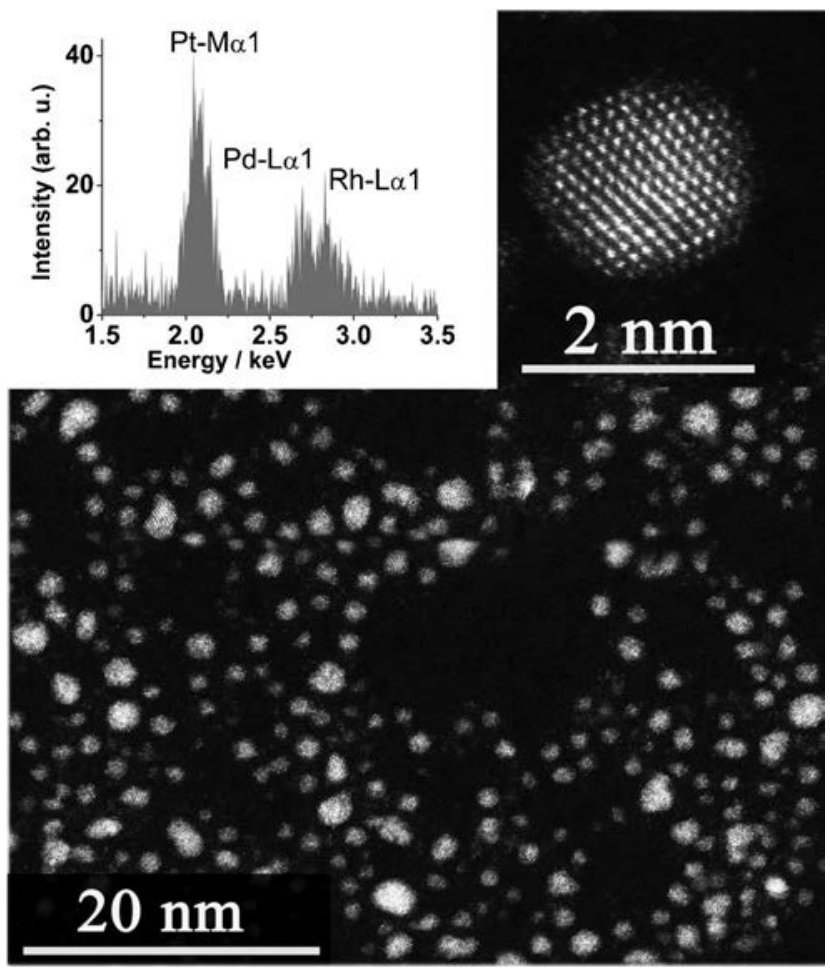

Fig. 3 STEM image of $\mathrm{Pt}_{45} \mathrm{Rh}_{27} \mathrm{Pd}_{28}$ trimetallic nanoparticles with mean diameters of $2.0 \pm 0.4 \mathrm{~nm}$. Insets correspond to the EDX contribution of Pt-M, $\mathrm{Pd}-\mathrm{L}$ and $\mathrm{Rh}-\mathrm{L}$ edges and a detailed magnification of a typical trimetallic nanoparticle.

After careful evaluation of multiple individual nanocrystals by EDX, the presence of additional Pt-(Pd) clusters could also be identified. This Pt-enriched composition is analogous to previous ternary alloys reported in the literature ${ }^{58,59}$ and is consistent with the above discussion on the higher reduction potentials of the platinum salt precursors. The re-evaluation of the aged colloidal dispersion after 3 months showed an increase of particle size distribution and an average composition of $\mathrm{Pt}_{42} \mathrm{Rh}_{29} \mathrm{Pd}_{29}$ (Fig. S11, ESI $\dagger$ ). Likewise, the aging process was accompanied by the re-dissolution of most of the monometallic and bimetallic clusters after random screening of multiple nanoparticles by EDX-STEM analysis. This fact further confirms the incorporation of new atoms to the ternary nanocrystals from the dissolution of the smaller clusters, as previously observed for the aged Pt-Ru bimetallic alloy (see Fig. S10, ESI $\dagger$ ).

\section{Conclusions}

We can conclude that the use of THPC as simultaneous reducing and stabilizing agent at room temperature in aqueous phase can be extended beyond the well-established synthesis of gold hydrosols to obtain a variety of monometallic, bimetallic and even trimetallic noble metal nanoparticles. These nanoparticles have a high potential for application in a variety of catalytic processes. 


\section{Notes and references}

1 B. Lim, M. J. Jiang, P. H. C. Camargo, E. C. Cho, J. Tao, X. M. Lu, Y. M. Zhu and Y. N. Xia, Science, 2009, 324, 1302-1305.

2 A. Mohanty, N. Garg and R. C. Jin, Angew. Chem., Int. Ed., 2010, 49, 4962-4966.

3 F. Bonet, V. Delmas, S. Grugeon, R. H. Urbina, P. Y. Silvert and K. Tekaia-Elhsissen, Nanostruct. Mater., 1999, 11, 1277-1284.

4 E. R. Essinger-Hileman, D. DeCicco, J. F. Bondi and R. E. Schaak, J. Mater. Chem., 2011, 21, 11599-11604.

5 R. Ferrando, J. Jellinek and R. L. Johnston, Chem. Rev., 2008, 108, 845-910.

6 C. J. Jia and F. Schuth, Phys. Chem. Chem. Phys., 2011, 13, 2457-2487.

7 Y. Li, Q. Y. Liu and W. J. Shen, Dalton Trans., 2011, 40, 5811-5826.

8 N. Toshima and T. Yonezawa, New J. Chem., 1998, 22, 1179-1201.

9 X. Wang, J. Zhuang, Q. Peng and Y. D. Li, Nature, 2005, 437, 121-124.

10 B. Singh, L. Murad, F. Laffir, C. Dickinson and E. Dempsey, Nanoscale, 2011, 3, 3334-3349.

11 N. R. Jana and X. G. Peng, J. Am. Chem. Soc., 2003, 125, 14280-14281.

12 N. Zheng, J. Fan and G. D. Stucky, J. Am. Chem. Soc., 2006, 128, 6550-6551.

13 D. S. Wang, Q. Peng and Y. D. Li, Nano Res., 2010, 3, 574-580.

14 H. Hirai, Y. Nakao and N. Toshima, Journal of Macromolecular Science-Chemistry, 1979, A13, 727-750.

15 N. Toshima, K. Kushihashi, T. Yonezawa and H. Hirai, Chem. Lett., 1989, 1769-1772.

16 T. Teranishi and M. Miyake, Chem. Mater., 1998, 10, 594-600.

17 A. Hoffman, J. Am. Chem. Soc., 1921, 43, 1684-1693.

18 A. Hoffman, J. Am. Chem. Soc., 1930, 52, 2995-2998.

19 W. A. Reeves, F. F. Flynn and J. D. Guthrie, J. Am. Chem. Soc., 1955, 77, 3923-3924.

20 D. G. Duff, A. Baiker and P. P. Edwards, Langmuir, 1993, 9, 2301-2309.

21 J. Turkevich and G. Kim, Science, 1970, 169, 873.

22 J. Turkevich, P. C. Stevenson and J. Hillier, Discuss. Faraday Soc., 1951, 11, 55.

23 G. Schmid and A. Lehnert, Angew. Chem., Int. Ed. Engl., 1989, 28, 780-781.

24 G. Schmid, A. Lehnert, J. O. Malm and J. O. Bovin, Angew. Chem., Int. Ed. Engl., 1991, 30, 874-876.

25 G. Schmid, Nanoparticles: From Theory to Application, WileyVCH GmbH \& Co. KGaA, Weinheim, 2004.

26 K. Kim, H. B. Lee, J. W. Lee, H. K. Park and K. S. Shin, Langmuir, 2008, 24, 7178-7183.

27 D. S. Wang, T. Xie and Y. D. Li, Nano Res., 2009, 2, 30-46.

28 I. Ohno, O. Wakabayashi and S. Haruyama, J. Electrochem. Soc., 1985, 132, 2323-2330.

29 J. E. A. M. van den Meerakker, J. Appl. Electrochem., 1981, 11, 387-393.

30 D. G. Duff, A. Baiker and P. P. Edwards, J. Chem. Soc., Chem. Commun., 1993, 96-98.
31 D. G. Duff, A. Baiker, I. Gameson and P. P. Edwards, Langmuir, 1993, 9, 2310-2317.

32 S. L. Westcott, S. J. Oldenburg, T. R. Lee and N. J. Halas, Langmuir, 1998, 14, 5396-5401.

33 M. R. Rasch, K. V. Sokolov and B. A. Korgel, Langmuir, 2009, 25, 11777-11785.

34 M. M. Mariscal, A. Mayoral, J. A. Olmos-Asar, C. Magen, S. Mejia-Rosales, E. Perez-Tijerina and M. Jose-Yacaman, Nanoscale, 2011, 3, 5013-5019.

35 D. R. Linde, Handbook of Chemistry and Physics, CRC Press, New York, 84th edn, 2003.

36 W. A. Reeves and J. D. Guthrie, Ind. Eng. Chem., 1956, 48, 64-67.

37 V. V. Agrawal, G. U. Kulkarni and C. N. R. Rao, J. Colloid Interface Sci., 2008, 318, 501-506.

38 U. Maitra, B. Das, N. Kumar, A. Sundaresan and C. N. R. Rao, ChemPhysChem, 2011, 12, 2322-2327.

39 C. Wang, M. F. Chi, D. G. Li, D. Strmcnik, D. van der Vliett, G. F. Wang, V. Komanicky, K. C. Chang, A. P. Paulikas, D. Tripkovic, J. Pearson, K. L. More, N. M. Markovic and V. R. Stamenkovic, J. Am. Chem. Soc., 2011, 133, 14396-14403.

40 J. Xu, T. White, P. Li, C. H. He, J. G. Yu, W. K. Yuan and Y. F. Han, J. Am. Chem. Soc., 2010, 132, 10398-10406.

41 H. Zhang, M. S. Jin, J. G. Wang, M. J. Kim, D. R. Yang and Y. N. Xia, J. Am. Chem. Soc., 2011, 133, 10422-10425.

42 H. Zhang, M. S. Jin, J. G. Wang, W. Y. Li, P. H. C. Camargo, M. J. Kim, D. R. Yang, Z. X. Xie and Y. A. Xia, J. Am. Chem. Soc., 2011, 133, 6078-6089.

43 G. L. Brett, Q. He, C. Hammond, P. J. Miedziak, N. Dimitratos, M. Sankar, A. A. Herzing, M. Conte, J. A. Lopez-Sanchez, C. J. Kiely, D. W. Knight, S. H. Taylor and G. J. Hutchings, Angew. Chem., Int. Ed., 2011, 50, 10136-10139.

44 Y. Kim, J. W. Hong, Y. W. Lee, M. Kim, D. Kim, W. S. Yun and S. W. Han, Angew. Chem., Int. Ed., 2010, 49, 10197-10201.

45 S. Proch and R. Kempe, Angew. Chem., Int. Ed., 2007, 46, 3135-3138.

46 N. Dimitratos, J. A. Lopez-Sanchez and G. J. Hutchings, Chem. Sci., 2012, 3, 20-44.

47 Y. Liu, M. F. Chi, V. Mazumder, K. L. More, S. Soled, J. D. Henao and S. H. Sun, Chem. Mater., 2011, 23, 4199-4203.

48 C. J. Zhong, J. Luo, P. N. Njoki, D. Mott, B. Wanjala, R. Loukrakpam, S. Lim, L. Wang, B. Fang and Z. C. Xu, Energy Environ. Sci., 2008, 1, 454-466.

49 S. T. Christensen, H. Feng, J. L. Libera, N. Guo, J. T. Miller, P. C. Stair and J. W. Elam, Nano Lett., 2010, 10, 3047-3051.

50 B. Lim, J. G. Wang, P. H. C. Camargo, M. J. Jiang, M. J. Kim and Y. N. Xia, Nano Lett., 2008, 8, 2535-2540.

51 J. Greeley, I. E. L. Stephens, A. S. Bondarenko, T. P. Johansson, H. A. Hansen, T. F. Jaramillo, J. Rossmeisl, I. Chorkendorff and J. K. Norskov, Nat. Chem., 2009, 1, 552-556.

52 W. Huang, J. N. Kuhn, C. K. Tsung, Y. Zhang, S. E. Habas, P. Yang and G. A. Somorjai, Nano Lett., 2008, 8, 2027-2034.

53 S. H. Joo, J. Y. Park, J. R. Renzas, D. R. Butcher, W. Y. Huang and G. A. Somorjai, Nano Lett., 2010, 10, 2709-2713.

54 H. Mori and H. Yasuda, Bull. Mater. Sci., 1999, 22, 181-187. 
55 B. N. Wanjala, J. Luo, R. Loukrakpam, B. Fang, D. Mott, P. N. Njoki, M. Engelhard, H. R. Naslund, J. K. Wu, L. C. Wang, O. Malis and C. J. Zhong, Chem. Mater., 2010, 22, 4282-4294.

56 Z. C. Xu, C. E. Carlton, L. F. Allard, Y. Shao-Horn and K. Hamad-Schifferli, J. Phys. Chem. Lett., 2010, 1, 2514-2518.

57 J. B. Xu, T. S. Zhao, Z. X. Liang and L. D. Zhu, Chem. Mater., 2008, 20, 1688-1690.

58 E. Antolini, Appl. Catal., B, 2007, 74, 324-336.
59 E. Antolini, Appl. Catal., B, 2007, 74, 337-350.

60 R. Venkataraman, H. R. Kunz and J. M. Fenton, J. Electrochem. Soc., 2003, 150, A278-A284.

61 B. N. Wanjala, B. Fang, R. Loukrakpam, Y. S. Chen, M. Engelhard, J. Luo, J. Yin, L. F. Yang, S. Y. Shan and C. J. Zhong, ACS Catal., 2012, 2, 795-806.

62 B. N. Wanjala, B. Fang, J. Luo, Y. S. Chen, J. Yin, M. H. Engehard, R. Loukrakpam and C. J. Zhong, J. Am. Chem. Soc., 2011, 133, 12714-12727. 